\title{
Society for Pediatric Research Presidential Address 1995: Marrying Our Medicine to Biology
}

\author{
DAVID H. PERLMUTTER
}

\begin{abstract}
Departments of Pediatrics, Cell Biology and Physiology, Washington University School of Medicine,
\end{abstract} Division of Gastroenterology and Nutrition, St. Louis Children's Hospital, St. Louis, Missouri 63110

, Friends, members, guests, it is a great pleasure for me to represent the SPR today, and to be a part of the academic pediatric community as it marks the 105th annual meeting of the American Pediatric Society and Society for Pediatric Research. Although I have still not fully reconciled myself to the tradition of the Presidential Address, I would like to use this time today to make several remarks that, nevertheless, come from my heart. I would like to particularly reflect on the rather striking ironies in the forces which are already reshaping medicine, and inevitably will reshape academic medicine. Of course one of these factors is what has been called the "new order," the "business of medicine," the "health care industry." I am sure that many of you feel as peculiar as I do when you go to the Doctor's lounge or the medical staff meeting and hear that your hospital is buying more practices, that it is buying other hospitals, or perhaps, that your hospital is becoming an insurance company. An article entitled "A Hospital Copes with the New Order" recently appeared on the front page of the Business Section of the January 29 Sunday New York Times describing the transformation of a large private hospital in San Francisco into what is ostensibly an insurance company (1). It took 5 years and they lost a lot of money but they discarded their plans for a cancer treatment building, contracted out their oncology services, released their transplant teams, converted their children's services into an outpatient surgery facility, and enrolled 107,000 individuals into their hospital-based health plan. And be assured that the best market analysis was used to recruit people who were likely to be healthy for a long time. The most interesting news buried in this article, however, is that of a similar transformation occurring in a hospital system of a major medical school. This is closer to home for me. Somehow, during these last 20 years of my life learning medicine and science I did not see myself working for an insurance company. It is more than enough for me to meet with my own State Farm agent once a year.

There can be no doubt that we have been discovered by Wall Street, by "Big Business." The Merrill Lynch man tells my father to invest in for-profit health care conglomerates, forget about the volatile computer industry. We have spawned a new form of law in this country, "health care law." My friend tells me that his firm is looking for more cracker-jack health care lawyers. They have already hired 12 to their new health care division in the last 4 years. Yes, there is cash in the "business of medicine." However, it is not in the hands of the patients or the the doctors, rather in the layers and layers of industry that surround us.

Even more ironic is the timing of this new order of the business of medicine. It seems to be coinciding with the emergence of what some have called the "New Biology." It is difficult to know exactly when the "New Biology" started and the "Old" ended, but there is something extraordinary happening. Even a cursory examination of the leading journals of the day suggests that we are in the throes of a biologic revolution. Several weeks ago a group of scientists put beads soaked in fibroblast growth factor in the flank of a chick embryo and found that it formed a new, entirely normal limb (2). A group from Baylor found by knocking out a single gene in embryonic stem cells that they could generate a mouse embryo with an entirely normal body but without any head (3).

This is fantastic, the pundits will say, but is there evidence that this biologic revolution, this "New Biology," can really influence our medicine, pediatric medicine? Is it relevant, they ask (4)? I would like to spend my remaining time reviewing four examples of basic biologic observations that have come to my attention in the last year. In each case, the observations are completely surprising, could not have been predicted, and I will argue, have profound implications for pediatric medicine.

The first example comes from a recent study by Yokoyama et al. (5) and relates to the disorder that we call biliary atresia. Let me give you the context of this discovery. Biliary atresia is a devastating condition in which there is a complete obstruction to bile flow and progressive liver failure (6). Eighty percent of these children ultimately undergo liver transplantation (7). In fact, these children account for approximately half of the 500 or so children who undergo liver transplantation in this country each year. The cost of their care to the medical system is now on the order of 70-100 million dollars per year if one just takes into consideration the cost of the transplant hospitalization. We have known about the disorder since the 1890 s when it was first described in the medical literature (8) but still know nothing about its pathogenesis. Until the Yokoyama study we didn't even know how to set up a system to study its pathogenesis. There is a relatively low incidence of affected family members and so it is not obviously genetic in origin. Specific environmental factors, such as infections and toxins, have been elusive. Several recent studies of the clinical characteristics of these patients have drawn greater attention to the subgroup of infants with biliary atresia, some $10-25 \%$ of 
the overall population, who also have anomalies of visceral symmetry $(9,10)$. These anomalies include intestinal malrotation, abdominal situs inversus, polysplenia, and anomalies of the portal vein and hepatic artery. In fact, if one examines the sequence of events that characterize the early embryonic morphogenesis of the intestine and hepatobiliary tree, one sees that the liver, and particularly the extrahepatic biliary tree, is considerably affected by the counterclockwise rotation of the intestine during development. Early in development, the primary intestinal loop forms. The cephalic limb elongates as the loop rotates counterclockwise $180^{\circ}$ around the axis of the superior mesenteric artery. This brings the transverse colon in front of the jejunum. The rotation continues to $270^{\circ}$ with elongation and looping of small intestine. The jejunum comes to lie left of the midline, and the cecum comes to lie in the right lower quadrant. This process also affects the development of the biliary tree. At the same time as the duodenum comes to rest in the retroperitoneum, the orientation and connection of the common bile duct, as it is presumably differentiating, goes from the anterior right to the posterior left of the developing intestine (11).

Yokoyama et al. were not particularly interested in embryology of the biliary system when they did a wonderful experiment, an experiment which nonetheless qualifies as a fishing expedition. They searched for gross phenotypic changes in transgenic mice as a result of random insertional mutagenesis of a tyrosinase transgene. This strategy permitted detection of insertional events by changes in ocular pigmentation and recovery of the disrupted gene flanking the insertion site of the transgene. In this way, a random insertional mutagenesis event would be used to identify specific genes for specific phenotypes, or for specific steps in embryogenesis. In one family of animals generated by this approach there was poor growth, the stomach was noted to be on the right side of the abdomen, and the animals died with severe jaundice in the first week of life. The anomalies included intestinal malrotation, mirror-image left-right inversions of stomach and liver. Some of the animals had polysplenia and preduodenal portal vein. Although it is not mentioned in the report, most of these animals have abnormal development of the common bile duct (Overbeek P, personal communication). The mutation, called inv, maps to a loci on mouse chromosome 4 and, in contrast to other models of left-right asymmetry such as the iv mutation $(12,13)$ and the $\mathrm{Ft}$ mutation (14) which affect $50 \%$ of homozygous progeny, it results in a situs abnormality in $100 \%$ of homozygous offspring. Presumably the gene mutated in this inv mouse ordinarily directs a critical phase in the morphogenic program for establishing embryonic visceral symmetry and for early development of the extrahepatic biliary tree. Cloning of the inv locus, ongoing as we speak, will allow us to determine the pathogenic mechanism for $10-25 \%$ of biliary atresia cases, to examine the possibility that milder defects in the inv gene cause biliary atresia in some of the remaining cases, to presumably make prenatal diagnoses and permit earlier therapeutic intervention. The inv mouse also provides an animal model for testing novel treatment strategies.

In the past year there has also been an extraordinary revelation about Hirschsprung's disease that arises from a surpris- ing and completely unpredicted biologic observation, my second example for today. Hirschsprung's disease, which affects 1 in 5000 live births, can be associated with extensive morbidity and even mortality. It involves a failure in the craniocaudal migration of neural crest-derived ganglionic precursors such that involved segments of bowel are devoid of ganglion cells in the myenteric plexus (15). Experimental studies done more than 40 years ago showed that the ganglia of the myenteric plexus were derived from the craniocervical neural crest and that precursors ordinarily migrate progressively downward to the rectum and genitourinary system during embryogenesis (Fig. 1). We now know that neural crest cells must migrate to several target tissues during embryogenesis. In Figure 2, the neural crest is shown dorsal to the neural tube and between somites. It is anterior to notochord, gastrointestinal tract, sympathetic ganglia, and adrenal glands. Target tissues include skin where neural crest cells become melanocytes, adrenal glands where they become chromaffin cells, sympathetic ganglia, the gastrointestinal tract as well as other tissues not shown here. Presumably the migration of these neural crest progenitor cells involves specific cues at specific times in morphogenesis. If this process is anything like what has been shown for neurons in the spinal cord, a process called chemotropism (16-18), then one would predict that specific diffusible factors released by cellular targets guide the progenitor cell toward its destination by interacting with specific receptors on the growth cone of the progenitor neuronal processes.

Yanagisawa and colleagues became aware of the concept of chemotropism when they observed the results of targeted disruption of the endothelin 3 gene in a knockout mouse (19). Endothelins are a family of 21-amino acid peptides that were originally identified as potent vasopressors derived from vascular endothelial cells (20). There are three endothelin peptides-EDN1, EDN2, and EDN3 are encoded by separate genes and expressed in a variety of tissues, and cell types, including cell types other than vascular endothelial cells (21). The effects of the endothelins are mediated by two different receptors, the endothelin $\mathrm{A}$ and endothelin $\mathrm{B}$ receptors. These receptors are also found in many tissues and cell types and have a tissue distribution which partially overlaps that of the endothelins themselves (22-24). Interestingly, the endothelin receptors are members of the $\mathrm{G}$ protein-coupled receptor family, a family which has 7-10 transmembrane domains and includes receptors for adrenergic hormones, neurotransmitters,

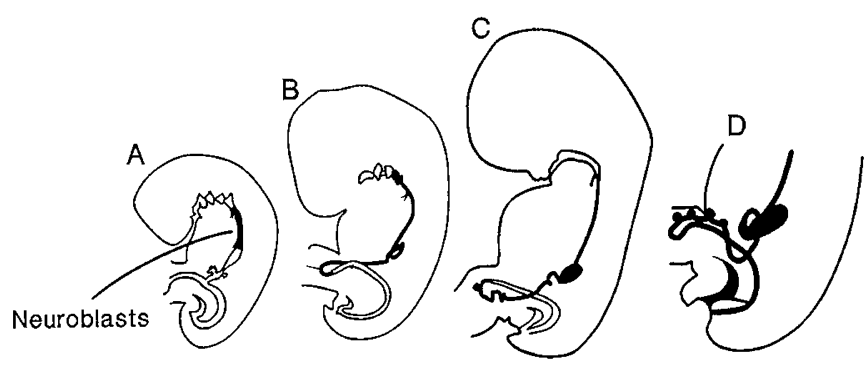

Figure 1. Progressive downward migration of neuroblasts into gastrointestinal and genitourinary system during embryonic development. (Reproduced with permission from T. Ehrenpreis: Hirschsprung's Disease. Year Book Medical Publishers, Chicago, 1970.) 


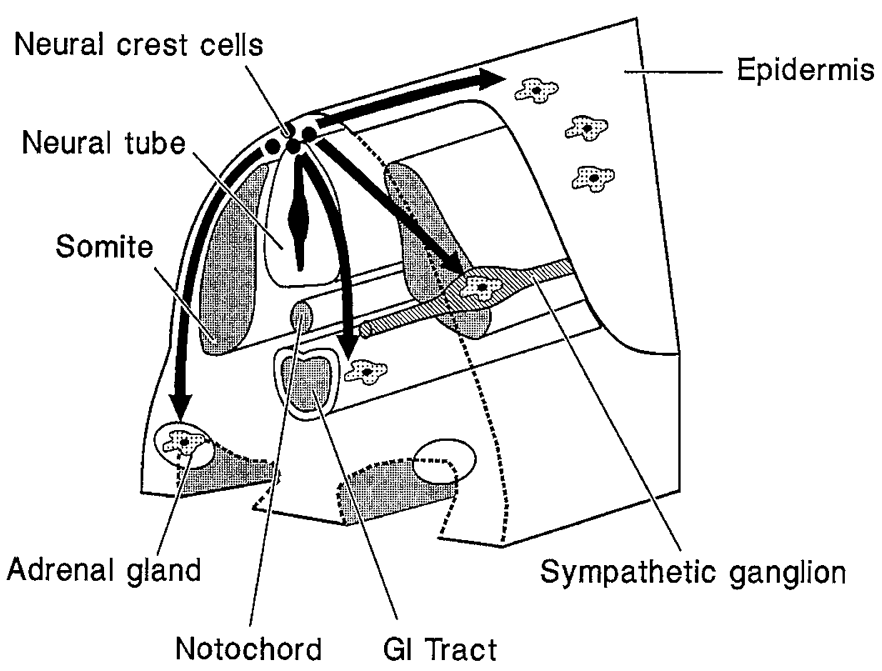

Figure 2. Migration of neural crest cells. Embryo shown in cross section to illustrate several tissues into which neural crest progenitors migrate and differentiate during development. (Adapted with permission from M. BronnerFraser: Segregation of cell lineage in the neural crest. Current Opinion in Genetics and Development 3:641-647, 1993.)

neuropeptides, as well as for chemotactic receptors. The chemotactic receptors mediate directed migration of cells toward their ligands. The Yanagisawa laboratory was interested in examining the physiology of the endothelin 3 peptide specifically and, thus, generated an endothelin 3 knockout mouse. The experiment was entirely successful, but there was no apparent abnormality in blood pressure or blood pressure control. Instead, the animals had aganglionic megacolon. In some cases, the entire colon was aganglionic. In other cases, the narrowed segment was confined to the rectum. This is very similar to what we see clinically in Hirschsprung's disease. Homozygous animals also had extensive white spotting of skin and coat and absence of melanocytes from these areas. These results were consistent with the concept that endothelin 3 is essential for the development and migration of two neural crestderived cell lineages, epidermal melanocytes and enteric ganglia.

Yanagisawa and colleagues then went on to show that targeted disruption of the endothelin B receptor is also associated with aganglionic megacolon and spotted coat color. Moreover, they found that the piebald-lethal mouse, a mouse strain which has long been studied as a model of megacolon and spotted coat color, is associated with a deletion of the endothelin B receptor gene (25). A Southern blot analysis of DNA from wild type and piebald-lethal mouse was hybridized with probes from the $5^{\prime}$ end, middle, and $3^{\prime}$ end of the endothelin B receptor gene. In each case there was no DNA fragment in the piebald-lethal mouse corresponding to the fragment in the wild type mouse. The deletion was shown to be specific by demonstrating the presence of identical DNA fragments in each case with endothelin A receptor cDNA probes.

The endothelin B receptor gene data were of great interest to these investigators because it was already known that this gene maps to chromosome 13 very close to the site to which previous investigators had mapped the Hirschsprung's disease of a large inbred Mennonite kindred. They also knew that Hirschsprung's disease in this kindred was associated with subtle abnormalities in pigmentation. This includes bicolored irides and hypopigmentation with spotting of the hands similar to that seen in the endothelin 3 and endothelin B receptorknockout mice. We now know from Yanagisawa and colleagues that the Hirschsprung disease susceptibility locus in this kindred is, in fact, the endothelin B receptor gene and that there is a missense mutation in the endothelin $\mathrm{B}$ receptor gene in the kindred (26). Figure 3 shows the endothelin B receptor with seven transmembrane domains, an amino-terminal extracellular tail, three extracellular loops, a carboxyl-terminal cytoplasmic tail, and three cytoplasmic loops. The Hirschsprung's mutation in the kindred is just outside the plasma membrane in the second extracellular loop, a location in the binding pocket shown to affect the coupling of ligand binding to signal transduction.

These data provide evidence that Hirschsprung's disease is a defect in ligand-receptor interactions which determine chemotropism of ganglion cells at specific stages in embryonic development and into specific segments of bowel. We now know that this concept is supported by startling research published in the last year and showing that Hirschsprung's disease in other kindreds can be caused by a mutation in the receptor tyrosine kinase RET (27-29). Mice with a mutation in the receptor tyrosine kinase KIT lack the enteric intestinal ganglia of Cajal and lack intestinal pacemaker activity (30). In short, specific ligand-receptor interactions direct neurons into intestine during embryogenesis. This is an extraordinary conceptual advance for our understanding of early development of intestine and its nervous innervation, but it also allows us to begin to more carefully characterize our patients, make diagnoses earlier, provide genetic counseling, and to establish frameworks for studying the basis of pediatric problems of even greater magnitude at least with respect to numbers. Do children with severe constipation have milder defects in the endothelin B receptor or RET?

Another extraordinary and revealing observation has recently been made by collaborators from the Cardiovascular Center at the Massachusetts General Hospital and the Department of Neuroscience at Johns Hopkins (31) who have been studying the role of NO in the physiology of the cardiovascular and nervous systems, respectively. NO is a gas that diffuses

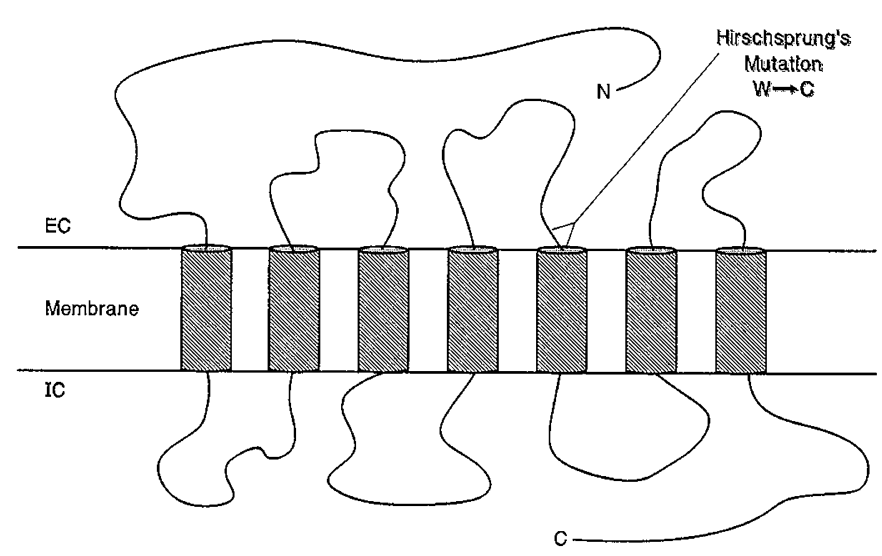

Figure 3. Endothelin B receptor structure and localization of the mutation that causes Hirschsprung's disease susceptibility. 
freely across membranes to activate guanylyl cyclase, increase cyclic GMP levels, and through cyclic GMP, transduces signals for a breathtaking array of biologic activities. NO is produced in macrophages, endothelial cells, neurons, and many other cell types through a pathway in which NOS is the rate-limiting step. There are at least two different forms of NOS (32). The constitutive form (cNOS) is found in endothelial cells and neurons. It is dependent on calmodulin and regulated by calcium. The inducible form, which is not dependent on calcium/calmodulin, is produced in macrophages upon activation by endotoxin or interferon- $\gamma$. In the cardiovascular system, endothelial NO is thought to play a key role in basal vascular tone and in vasodilation during stress. In the nervous system, NOS is concentrated in specific areas, which has led to the speculation that NO plays an important role in synaptic plasticity (33). It is also found in peripheral nerves and believed to play a role in intestinal smooth muscle relaxation during feeding as well as in innervation of erectile tissue. It was, thus, of great interest to Huang and colleagues to generate an animal model in which the cNOS gene was subjected to targeted disruption (31). The experiment was a complete success, resulting in absence of cNOS expression in the brain and endothelial cells of the knockout mice. To the great surprise of the investigators, there was only one major abnormality in the animals. The structure and function of the CNS and peripheral nervous system were normal. Behavior and reproductive capabilities were also preserved. The surprise was in a lowly, although ancient organ, the stomach. Homozygous mutant mice had markedly dilated stomachs with hypertrophy of the pyloric circular muscular layer. These animals had pyloric stenosis - that is, a phenotype that closely resembles the disorder we see in $\sim 1$ of every 3000 newborns (34). Indeed, it has recently been shown at this meeting, as well as in published reports, that NOS activity is completely absent in neurons that innervate pyloric circular muscle of infants with hypertrophic pyloric stenosis (35). Of course, cNOS can be detected in other tissues of infants with pyloric stenosis so that it is unlikely that the condition involves a genetic deficiency of cNOS. Perhaps there is a defect in the mechanism for region-specific, developmental stage-specific expression of cNOS in the nerves that innervate the pylorus. Perhaps there is a disturbance in cNOS activity in the more common affliction which has been dubbed with the name "pylorospasm" in the older textbooks of Pediatrics. Even more interesting is the idea that other disorders of gastrointestinal muscle, such as achalasia, may involve a similar mechanism, albeit in a different region of the alimentary tract.

In addition to providing novel information about pathogenesis, the knockout mouse strategy, described in the above examples, provides an animal model, a highly desirable system for testing new therapeutic strategies. My fourth example for today is another knockout mouse experiment which led to a wonderful serendipitous biologic observation and far-reaching implications for pediatric medicine. A group from the Netherlands Cancer Institute published the results of disrupting the gene for one of the multidrug resistance proteins, MDRla, in a knockout mouse (36). The MDR proteins were discovered almost 20 years ago as proteins induced in tumor cells by chemotherapeutic drugs and capable of conferring resistance to these drugs on the tumor cells (37). The MDR proteins actually act as pumps and are able to pump a wide range of structurally unrelated amphophilic hydrophobic drugs out of cells, including vinca alkaloids, anthracyclines, actinomycin, and cyclosporin A among others. The MDR proteins may also be involved in excretion of toxic metabolic intermediates and xenobiotics and may play a role in regulating cell volume by extruding chloride (reviewed in Ref. 38). Studies done in the last several years have shown that several compounds, such as verapamil, may inhibit the MDR proteins. Drugs like verapamil are now being used in phase I and phase II trials as reversal agents in patients to reduce the MDR-mediated resistance of clinical tumors (reviewed in Ref. 39). Each of the MDR proteins has multiple transmembrane spanning domains and two intracellular nucleotide binding regulatory regions (Fig. 4, left panel). Presumably drugs entering from outside the cell or accumulating into the cytoplasm are pumped, with energy generated by multiple rounds of ATP binding and hydrolysis, through the channel created by this extraordinary structure (Fig. 4, right panel). With this in mind, Borst and colleagues reported on the knockout of MDR1a (36). Again the experiment was successful. MDR could not be detected in any tissue. The mice were viable, fertile, and phenotypically normal but, as predicted, accumulated vinblastine in tissues and body fluids to a markedly increased level. The eureka occurred, however, when workers in the animal facility became concerned about a mite infestation. All of the mice were sprayed with a dilute solution of an anthelminthic compound, ivermectin. A number of the animals then died with a paralytic illness. In systematic experiments it was shown that the knockout mice died at a dose of ivermectin 500-fold lower than those of wild type mice. The most important experiment showed that the levels of ivermectin in the brain of the knockout mouse were 50-100-fold higher than those of the wild type mouse. Sure enough, when one looks back at previous studies there is extremely high levels of MDR1a expression in brain endothelium. The results of this experiment suggest that MDR is in the brain endothelium for a reason and imply that MDR contributes to the protective function of the blood-brain barrier by pumping drugs such as ivernectin out of the brain. We usually think of the blood-brain barrier as a means for providing pharmacologic sanctuary to the brain, rendering it inaccessible to a range of

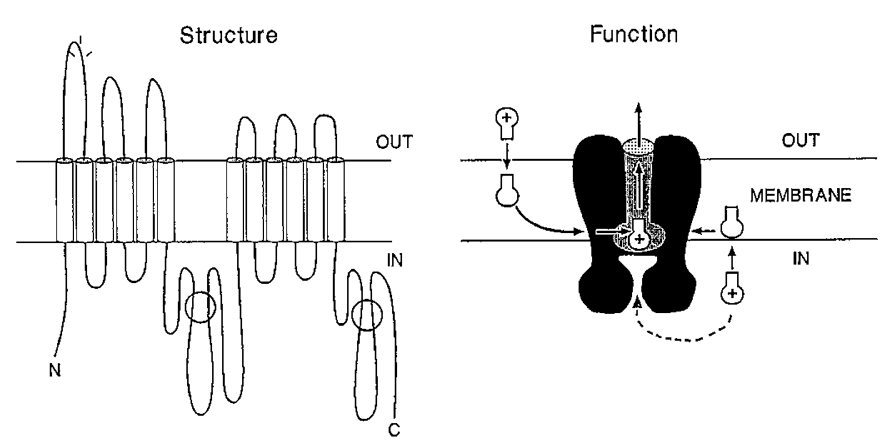

Figure 4. Multidrug resistance proteins. Conceptual model of structure (left) and function (right). (Adapted with permission from M. M. Gottesman and I. Pastan: Biochemistry of multidrug resistance mediated by the multidrug transporter. Annual Review of Biochemistry 62:385-427, 1993.) 
drugs. The blood-brain barrier consists of nonfenestrated endothelial cells, linked to each other by tight junctions, and covering the walls of the brain capillaries. Its anatomy acts as a continuous, lipophilic, physical barrier, blocking passage of hydrophilic solutes in either direction (40). It is now possible to conceptualize the MDR proteins as providing a potentially even more significant physiologic protective barrier. It is also possible to imagine taking advantage of the MDR proteins to minimize penetration of certain drugs into the brain and, in blocking MDR proteins, to enhance the penetration of other drugs into the brain.

Yes, experiments like these can influence the practice of Pediatrics. And often it is the result that is not planned that has the greatest impact. I doubt whether the business of medicine, the "new order," has the vision to support this type of work. Perhaps, it is our business to ensure its survival. In no way am I implying that I know exactly how we will do so, but I think there are at least a few principles. First, we cannot compromise our resolve for research and scholarship in the Department of Pediatrics even when faced by the extreme pressures of our "managers" to balance the ledger, to do away with that which is least essential. Second, we cannot jump too quickly onto the bandwagon for the quick fix of "applied research." Our most important discoveries and revelations, even unplanned, evolve from years of methodical work in basic research. Third, we must constantly reeducate ourselves, reading, listening, availing ourselves of the rich intellectual resources in our medical schools and universities. Fourth, we must look at our patients even more carefully than before, record their characteristics systematically, and challenge our assumptions about them. In this we will have prepared our minds for the surprising connection between biologic observations and the care of our patients. Fifth, we imbue our young with the core values handed down by generations of giants in Pediatrics. From Park to Holt to Janeway to the current giants, Rudolph, Nathan, Shapiro, and for those of us from the Midwest who have been lucky enough, Colten, the value system of hard work, intelligence, creativity, curiosity, inspiration, and of course, compassion is what we promise the good reputation of our wonderful profession and what we promise our patients, their parents, and their families.

\section{REFERENCES}

1. Eckholm E 1995 A hospital copes with the new order. New York Times 3:1, Jan 29

2. Cohn MJ, Izpisua-Belmonte JC, Abad H, Heath JK, Tickle C 1995 Fibroblast growth factors induce additional limb development from the flank of chick embryos. Cell 90:739-746

3. Shawlot W, Behringer RR 1995 Requirement for Lim 1 in head-organizer function. Nature 374:425-430

4. Thomas L 1974 The Lives of a Cell: Notes of a Biology Watcher. Penguin Books, New York, pp. 118-119

5. Yokoyama T, Copeland NG, Jenkins NA, Montgomery CA, Elder FFB, Overbeek PA 1993 Reversal of left-right asymmetry: a situs inversus mutation. Science 260:679682

6. Stein JE, Vacanti JP 1994 Biliary atresia and other disorders of the extrahepatic biliary tree. In: Suchy FJ (ed) Liver Disease in Children. CV Mosby, St. Louis, pp 426-442

7. Laurent J, Gauthier F, Bernard O, Hadchouel M, Odievre M, Valayer J, Alagille D 1990 Long-term outcome after surgery for biliary atresia: study of patients surviving for more than 10 years. Gastroenterology 99:1793-1797

8. Thomson J. 1982 On congenital obliteration of the bile ducts. Edinb Med J 37:606

9. Carmi R, Magee CA, Neill CA, Karrer FM 1993 Extrahepatic biliary atresia and associated anomalies: etiologic heterogeneity suggested by distinctive patterns of associations. Am J Med Genet 45:683-693
10. Karrer FM, Hall RJ, Lilly JR 1991 Biliary atresia and the polysplenia syndrome. J Pediatr Surg 26:524-527

11. Severn CB 1972 A morphological study of the development of the human liver. II. Establishment of liver parenchyma, extrahepatic ducts and associated venous channels. Am J Anat 133:85-108

12. Brueckner M, D’Eustachio P, Horwich AL 1989 Linkage mapping of a mouse gene, iv, that controls left-right asymmetry of the heart and viscera. Proc Natl Acad Sci USA 86:5035-5038

13. Hanzlik AJ, Binder M, Layton WM, Rowe L, Layton M, Taylor BA, Osemlak MM, Richards JE, Kurnit DM, Stewart GD 1990 The murine situs inversus viscerum gene responsible for visceral asymmetry is linked tightly to the Igh-C cluster on chromosome 12. Genomics 7:389-393

14. Van der Hoeven F, Schimmang T, Volkmann A, Mattei M-G, Kyewski B, Ruther U 1994 Programmed cell death is affected in the novel mouse mutant fused toes $(\mathrm{Ft})$. Development 1206:2601-2607

15. Kirschner BS 1991 Hirschsprung's disease. In: Walker WA, Durie PR, Hamilton JR, Walker-Smith JA, Watkins JB (eds) Pediatric Gastrointestinal Disease. BC Decker, Philadelphia, pp 829-832

16. Kennedy TE, Serafini T, de la Torre JR, Tessier-Lavigne M 1994 Netrins are diffusible chemotropic factors for commissural axons in the embryonic spinal cord. Cell 78:425-435

17. Serafini T, Kennedy TE, Galko MJ, Mirzyan C, Jessell TM, Tessier-Lauigne M 1994 The netrins define a family of axon outgrowth-promoting proteins homologous to $C$. elegans UNC-6. Cell 78:409-424

18. Defelipe C, Pinnock RD, Hunt SP 1995 Modulation of chemotropism in the developing spinal cord by substance P. Science 267:899-902

19. Baynash AG, Hosoda K, Giaid A, Richardson JA, Emoto N, Hammer RE, Yanagisawa M 1994 Interaction of endothelin-3 with endothelin-B receptor is essential for development of epidermal melanocytes and enteric neurons. Cell 79:1277-1285

20. Yanagisawa M, Kurihara H, Kimura S, Tomobe Y, Kobayashi M, Mitsui Y, Yazaki Y, Goto K, Masaki T 1988 A novel potent vasoconstrictor peptide produced by vascular endothelial cells. Nature 332:411-415

21. Rubanyi GM, Polokoff MA 1994 Endothelins: molecular biology, biochemistry, pharmacology, physiology and pathophysiology. Pharmacol Rev 46:325-415

22. Arai H, Hori S, Aramori I, Ohkubo H, Nakanishi S 1990 Cloning and expression of a cDNA encoding an endothelin receptor. Nature 348:730-732

23. Sakamoto A, Yanagisawa M, Sawamura T, Enoki T, Ohtani T, Sakurai T, Nakao K, Toyo-oka T, Masaki T 1993 Distinct subdomains of human endothelin receptors determine their selectivity to $\mathrm{ET}_{\mathrm{A}}$-selective antagonist and $\mathrm{ET}_{\mathrm{B}}$-selective agonists. J Biol Chem 268:8547-8553

24. Sakurai T, Yanagisawa M, Takuwa Y, Miyazaki H, Kimura S, Goto K, Masaki T 1990 Cloning of a cDNA encoding a non-isopeptide-selective subtype of the endothelin receptor. Nature 348:732-735

25. Hosoda K, Hammer RE, Richardson JA, Baynash AG, Cheung JC, Giaid A, Yanagisawa M 1994 Targeted and natural (Piebald-lethal) mutations of endothelin-B receptor gene produce megacolon associated with spotted coated color in mice. Cell 79:1267-1276

26. Puffenberger EG, Hosoda K, Washington SS, Nakao K, de Witt D, Yanagisawa M Chakravarti A 1994 A missense mutation of the endothelin-B receptor gene in multigenic Hirschsprung's disease. Cell 79:1257-1266

27. Romeo G, Ronchetto P, Luo Y, Barone V, Seri M, Caceherini I, Pasini B, Bocriardi R, Lerone M, Kaarlainen H, Martuccielli G 1994 Point mutations affecting the tyrosine kinase domain of the RET proto-oncogene in Hirschsprung's disease. Nature 369:377-378

28. Edery P, Lyonnet S, Mulligan LM, Pelet A, Dow E, Abel L, Holder S, Nihoul-Fekete C, Ponder BAJ, Munnich A 1994 Mutations of the RET proto-oncogene in Hirschsprung's disease. Nature 367:378-380

29. Schuchardt A, D'Agati V, Larsson-Blomberg L, Constantini F, Pachnis V 1994 Defects in the kidney and enteric nervous system of mice lacking the tyrosine kinase receptor RET. Nature 367:380-383

30. Huizinga JD, Thuneberg L, Kluppel M, Malysz J, Mikkelson HB, Bernstein A 1995 W/kit gene required for intestinal cells of Cajal and for intestinal pacemaker activity. Nature 373:347-349

31. Huang PL, Dawson TM, Bredt DS, Snyder SH, Fishman MC 1993 Targeted disruption of the neuronal nitric oxide synthase gene. Cell 75:1273-1286

32. Marletta MA 1993 Nitric oxide synthase structure and mechanism. J Biol Chem 268:12231-12234

33. Bredt DS, Huang PL, Snyder SH 1990 Localization of nitric oxide synthase indicating a neural role for nitric oxide. Nature 347:768-770

34. Spicer PD 1982 Infantile hypertrophic pyloric stenosis: a review. Br J Surg 69:128135

35. Vanderwinden J-M, Mailleux P, Schiffmann SN, Vanderhaeghen J-J, DeLaet M-H 1992 Nitric oxide synthase activity in infantile hypertrophic pyloric stenosis. N Engl J Med 327:511-515

36. Schinkel AH, Smit JJM, van Tellingen O, Beijnen JH, Wagenaar E, van Deemter L, Mol CAAM, van der Valk MA, Robanus-Maandag EC, te Riele HPJ, Berns AJM Borst P 1994 Disruption of the mouse mdr la p-glycoprotein gene leads to a deficiency in the blood-brain barrier and to increased sensitivity to drugs. Cell 77:491-502

37. Juliano RL, Ling V 1976 A surface glycoprotein modulating drug permeability in Chinese hamster ovary cell mutants. Biochim Biophys Acta 455:152-162

38. Gottesman MM, Pastan I 1993 Biochemistry of multidrug resistance mediated by the multidrug transporter. Annu Rev Biochem 62:385-427

39. Sikic BI 1993 Modulation of multidrug resistance: at the threshold. J Clin Oncol $11: 1629-1635$

40. Begley DJ 1993 Peptides and the blood-brain barrier: the status of our understanding. Ann NY Acad Sci 739:89-100 